\title{
Model Konseptual Penerapan Tata Kelola TI PLN Pembangkitan Sumbagsel Berdasarkan COBIT 5
}

\author{
Muhammad Rizky Pribadi ${ }^{1)}$, Hafidz Irsyad $^{2)}$ \\ ${ }^{1) 2)}$ Jurusan Teknik Informatika, STMIK Global Informatika MDP \\ Jl.Rajawali No. 14, Palembang. Kode pos : 30113 \\ Email : rizky@mdp.ac.id ${ }^{1)}$, hafizirsyad@mdp.ac.id ${ }^{2}$
}

\begin{abstract}
The implementation of IT governance in BUMN is a must. This is because BUMN use IT as an innovative service upgrade, both internal and external services. In the IT Governance there are several problems, such as the use of IT sometimes not in line with expectations, where an increasingly large IT investment was not followed by the increasing support for achieving the goals and strategies of companies / institutions. COBIT 5 is a renewed version that brings together cutting-edge thinking in engineering and IT governance. COBIT 5 is developed based on COBIT 4.1 by integrating Val IT and Risk IT from ISACA, ITIL, and relevant standards from ISO. Seven enablers of COBIT 5 standards are used as criteria in applying IT governance models in this study. PT PLN (Persero) Pembangkitan Area South Sumatra (PLN KITSBS) is one of the BUMN located in Southern Sumatra. PLN KITSBS is one of the generating units of PT PLN (Persero) which seeks the generation and supply of electricity in sufficient quantity and quality. PLN KITSBS has a capable power capacity of 2765 MW. PLN KITSBS has 10 (ten) generating sectors with work areas spread in South Sumatera, Bengkulu, Jambi, West Sumatera and Bandar Lampung. The research method used in this research is qualitative method, by doing case study approach. The result of this research is a draft of conceptual model of IT governance at PLN Pembangkitan Sumatera Selatan.
\end{abstract}

Keywords : Conceptual model,IT governance,COBIT 5, PLN

\begin{abstract}
Abstrak
Penerapan tata kelola TI di BUMN merupakan sebuah hal yang menjadi keharusan. Hal tersebut dikarenakan BUMN menggunakan TI sebagai inovasi pengingkatan layanan, baik layanan internal maupun eksternal. Dalam Tata Kelola TI terdapat beberapa masalah, diantaranya penggunaan TI kadang tidak sesuai dengan harapan, dimana investasi TI yang semakin besar ternyata tidak diikuti dengan dukungan yang semakin besar pula terhadap pencapaian tujuan dan strategi perusahaan/institusi. COBIT 5 adalah sebuah versi pembaharuan yang menyatukan cara berpikir yang mutakhir di dalam teknik dan tata kelola TI.COBIT 5 dikembangkan berdasarkan COBIT 4.1 dengan mengintegrasikan Val IT dan Risk IT dari ISACA, ITIL, dan standar yang relevan dari ISO. Seven enabler standar COBIT 5 digunakan sebagai kriteria dalam penerapan model tata kelola TI pada penelitian ini. PT PLN (Persero) Pembangkitan Area Sumatera Bagian Selatan (PLN KITSBS) merupakan salah satu BUMN yang berada di Sumatera Bagian Selatan. PLN KITSBS adalah salah satu unit pembangkitan PT PLN (Persero) yang mengusahakan pembangkitan dan penyediaan tenaga listrik dalam jumlah dan mutu yang memadai. PLN KITSBS ini mempunyai kapasitas daya mampu sebesar 2765 MW. PLN KITSBS memiliki 10 (sepuluh) sektor pembangkitan dengan wilayah kerja yang tersebar di Provinsi Sumatera Selatan, Bengkulu, Jambi, Sumatera Barat dan Bandar Lampung. Metode peneltian yang digunakan dalam penelitian ini adalah metode kualitatif, dengan melakukan pendekatan studi kasus. Hasil dari penelitian ini adalah sebuah rancangan model konseptual tata kelola TI pada PLN Pembangkitan Sumatera Bagian Selatan.
\end{abstract}

Kata kunci : Model Konseptual, Tata Kelola TI, COBIT 5, PLN 


\section{Pendahuluan}

Saat ini perkembangan TI yang demikian pesat memberikan peluang kepada BUMN untuk memberikan sebuah inovasi layanan berbasis TI kepada masyarakat. TI dalam pelaksanaannya membutuhkan pengaturan atau pengelolaan oleh BUMN, agar informasi dalam BUMN tersebut telah mendukung tujuan utama BUMN dalam melayani masyarakat, sumber daya digunakan secara tepat dan bertanggung jawab, risiko TI dapat dikelola secara cepat.

Tata kelola TI sangat diperlukan dalam BUMN untuk mengelola informasi yang merupakan aset penting bagi pemerintah. Hasil survei yang dilakukan oleh IT Governance nstitute (ITGI) yang tertuang dalam IT Governance Global Status Report tahun 2008 antara lain menyebutkan bahwa $63 \%$ responden menyatakan TI sangat penting bagi organisasinya, survei ini dilakukan juga terhadap para CIO dan CEO yang ada di Indonesia.

Dalam Tata Kelola TI terdapat beberapa masalah, diantaranya penggunaan TI kadang tidak sesuai dengan harapan, dimana investasi TI yang semakin besar ternyata tidak diikuti dengan dukungan yang semakin besar pula terhadap pencapaian tujuan dan strategi perusahaan/institusi. Inilah yang disebut "ProdutivityParadox".

PT PLN (Persero) Pembangkitan Area Sumatera Bagian Selatan (PLN KITSBS) merupakan salah satu BUMN yang berada di Sumatera Bagian Selatan. PLN KITSBS adalah salah satu unit pembangkitan PT PLN (Persero) yang mengusahakan pembangkitan dan penyediaan tenaga listrik dalam jumlah dan mutu yang memadai. PLN KITSBS ini mempunyai kapasitas daya mampu sebesar 2765 MW. PLN KITSBS memiliki 10 (sepuluh) sektor pembangkitan dengan wilayah kerja yang tersebar di Provinsi Sumatera Selatan, Bengkulu, Jambi, Sumatera Barat dan Bandar Lampung. Dengan area pekerjaan yang besar membuat PLN KITSBS membutuhkan inovasi TI dalam meningkatkan kinerja PLN KITSBS. Saat ini dalam menunjang kegiatan operasional, PLN KITSBS sudah menggunakan layanan TI seperti ERP, EProc, Email Korporat, A2K (Aplikasi Anggaran Keuangan), BBO (Batubara Online), PMO (Program Management Office), dll. Berbagai layanan aplikasi berbasis TI terus dikembangkan untuk dapat mendukung operasional layanan PLN Pembangkit Sumbagsel secara optimal. Terkait dengan hal tersebut, adanya kesadaran bahwa dibutuhkan sebuah solusi tata kelola TI yang diharapkan mampu untuk membuat proses layanan TI yang ada di PLN Pembangkit Sumbagsel lebih efektif dan efisien. Untuk mengetahui apa saja komponen yang perlu diperhatikan pada saat penerapan tata kelola TI yang akan dilakukan oleh PLN Pembangkit Sumbagsel, makan penelitian ini diharapkan dapat memberikan kontribusi keilmuan dalam bentuk sebuah model konseptual.

\section{A. Metode Penelitian}

Secara garis besar, penelitian ini akan mendeskripsikan bagaimana penerapan tata kelola TI yang terjadi di PT PLN Pembangkitan Sumbagsel (PLN KITSBS). Penelitian ini akan menggunakan studi kasus, karena dengan studi kasus penulis dapat mendapatkan suatu pemahaman tentang suatu kejadian.

\section{Pendekatan Kualitatif}

Metode penelitian kualitatif adalah penelitian yang bermaksud untuk memahami fenomena tentang apa yang dialami oleh subjek penelitian misalnya perilaku, persepsi, motivasi, tindakan, dll., secara holistik, dan dengan cara deskripsi dalam bentuk kata-kata dan bahasa, pada suatu konteks khusus yang alamiah dan dengan memanfaatkan berbagai metode alamiah (Moloeng, 2004).

\section{Studi Pustaka}

Studi pustaka dilakukan dengan mengumpulkan beberapa teori, metode ataupun model pada bidang manajemen sistem informasi atau TI pada umumnya, dan juga TI pada khususnya. Teori, metode maupun model tersebut merupakan metode yang banyak digunakan dan menjadi acuan dalam kegiatan akademis, industri maupun praktisi TI pada umumnya.

\section{a. Tata Kelola TI}

Ada banyak definisi Tata Kelola TI diantaranya : pengertian Tata Kelola TI menurut ITGI (ITGI, 2003): IT Governance is the responsibility of the board of directors and executive management. IT is an integral part of enterprise governance and consist of theleadership and organizational structures and processes that ensure that the organization's TI sustains and extends the organization'sstrategies and objectives.

Dari definisi diatas dapat diartikan bahwa Tata Kelola TI adalah tanggung jawab dari pimpinan puncak dan manajemen eksekutif dari suatu perusahaan. Dijelaskan pula bahwa Tata Kelola TI merupakan bagian dari pengelolaan perusahaan secara keseluruhan yang terdiri dari kepemimpinan dan struktur organisasi dan proses yang ada adalah untuk memastikan kelanjutan TI organisasi dan pengembangan strategi dan tujuan dari organisasi.

Sedangkan menurut Weill dan Ross(2004). Tata Kelola TI adalah:Specifying the decision rights and accountability framework to encourage desirable behaviour in using IT.

Dari pengertian diatas dapat dilihat bahwa tata kelola TI merupakan sebuah kerangka kerja yang spesifik dalam pengambilan keputusan dan akuntabilitas untuk mendukung perusahaan dalam menjalankan TI diperusahaan.

Menurut Grembeergen, Haes, dan Gudentops (2004). IT Governance adalah:IT Governance is the organizational capacity exercised by the Board, executive management and IT management to control the formulation and implementation of IT strategy and in this way ensure the fusion of business and IT.

Dari kutipan diatas, dijelaskan bahwa tata kelola TI merupakan tindakan organisasional yang dilakukan oleh dewan, manajemen eksekutif dan juga manajemen TI 
untuk mengendalikan formulasi dan implementasi dari strategi TI dan caranya untuk meyakini bisnis TI itu sendiri.

Berdasarkan dari beberapa definisi diatas dapat dilihat bahwa penekanan Tata Kelola TI adalah untuk menciptakan TI dapat berjalan selaras dengan bisnis organisasi dan pihak manajemen memiliki peranan sangat penting dalam implementasinya.

\section{b. COBIT 5}

COBIT 5 merupakan kerangka kerja tata kelola TI yang baru dirilis pada Juni 2012 lalu. COBIT 5 adalah sebuah versi pembaharuan yang menyatukan cara berpikir yang mutakhir di dalam teknik dan tata kelola TI. Ada perubahan dari COBIT sebelumnya yaitu COBIT 4.1 ke COBIT 5. COBIT 5 dikembangkan berdasarkan COBIT 4.1 dengan mengintegrasikan Val IT dan Risk IT dari ISACA, ITIL, dan standar yang relevan dari ISO. Terdapat proses-proses baru yang sebelumnya belum ada di COBIT 4.1. Dengan demikian proses-proses pada COBIT 5 ini lebih holistik, lengkap dan mencakup aktivitas bisnis dan IT secara end-to-end.

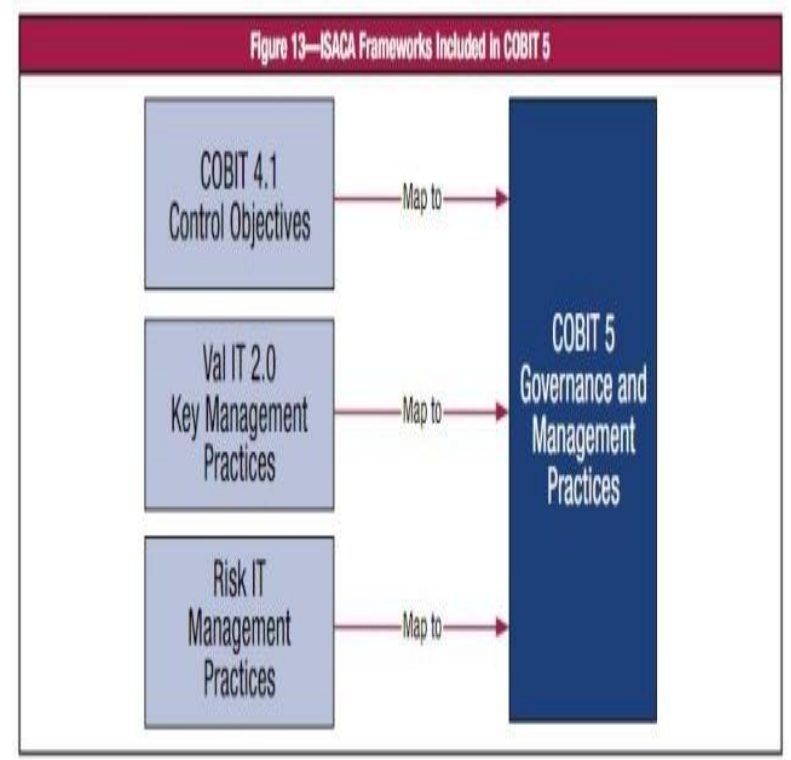

Gambar 1. Pemetaan Komponen dari COBIT 4.1, Val IT, dan Risk IT ke COBIT 5

Sumber: ISACA, 2012

Untuk melihat lebih jelas perubahan yang dibawa oleh COBIT 5, dibawah ini akan dijelaskan secara rinci:

1. Prinsip baru dalam tata kelola TI untuk organisasi,

Governanceof Enterprise IT (GEIT).

COBIT 5 lebih berorientasi pada prinsip, dibandingkan pada proses yang dibuat berdasarkan feedback yang masuk, ternyata pengguna prinsip-prinsip lebih mudah dipahami dan diterapkan dalam konteks enterprise secara lebih efektif. Gambar dibawah ini menunjukkan COBIT 5 principles.

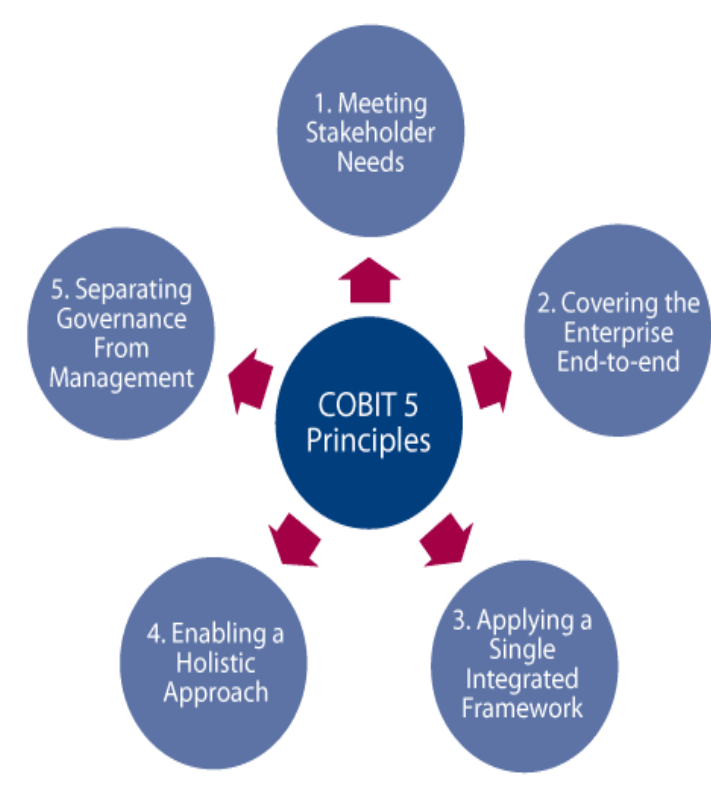

Gambar 2. COBIT 5 Principles

2. COBIT 5 memberi penekanan lebih kepada enabler dan menyebutkan secara spesifik ada tujuh enablerdalam implementasinya.

3. COBIT 5 mendefinisikan model referensi proses yang baru dengan tambahan domain governance dan beberapa proses yang sama sekali baru ataupun modifikasi proses lama serta mencakup aktivitas organisasi secara endtoend. Selain mengkonsolidasikan COBIT 4.1, Val IT, dan Risk IT dalam sebuah framework, COBIT 5 juga dimuktahirkan untuk penyelarasan dengan bestpracticesyang ada seperti misalnya ITIL v3 dan TOGAF.

4. Seperti disinggung sebelumnya, bahwa dalam COBIT 5 terdapat proses-proses baru yang sebelumnya belum ada di COBIT 4.1, serta beberapa modifikasi pada proses yang sudah ada sebelumnya di COBIT 4.1. secara sederhana dapat dikatakan bahwa model referensi proses COBIT 5 sebenarnya mengintegrasikan konten COBIT 4.1, Risk IT dan Val IT.

5. COBIT 5 menyediakan konsep goal dan metrik yang sama dengan COBIT 4.1, Val IT, dan Risk IT. Hanya saja COBIT 5 mengubah namanya menjadi enterprisegoal, IT related goal dan process goal untuk mencerminkan view secara organisasi.

6. Framework COBIT 5 menyediakan input dan output untuk setiap management practice, sementara COBIT 4.1 hanya menyediakan ini pada tingkatan proses saja.

Berikut kerangka kerja pada COBIT dan hubungan antara kelima COBIT 5. 


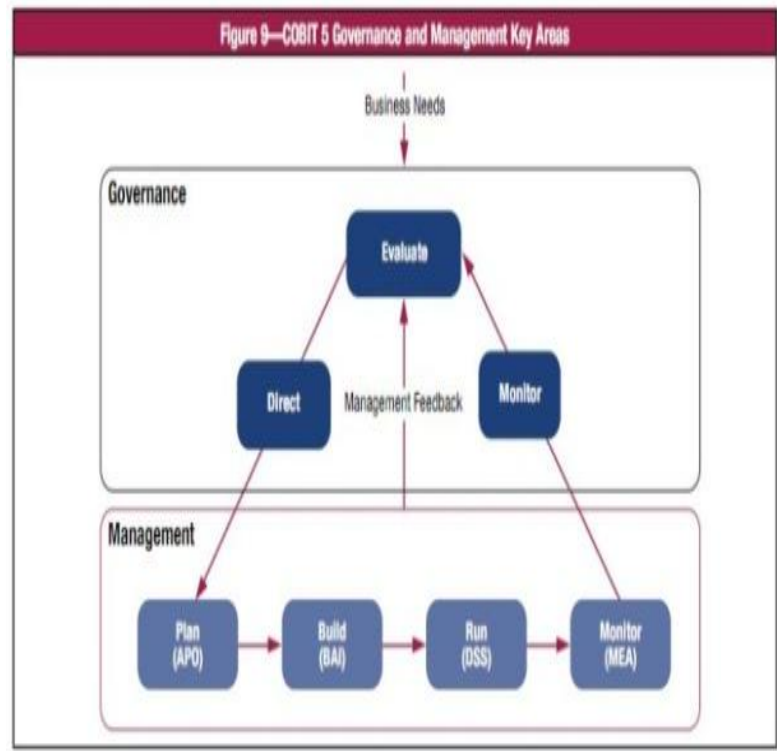

Gambar 3. Hubungan Kelima Domain COBIT 5

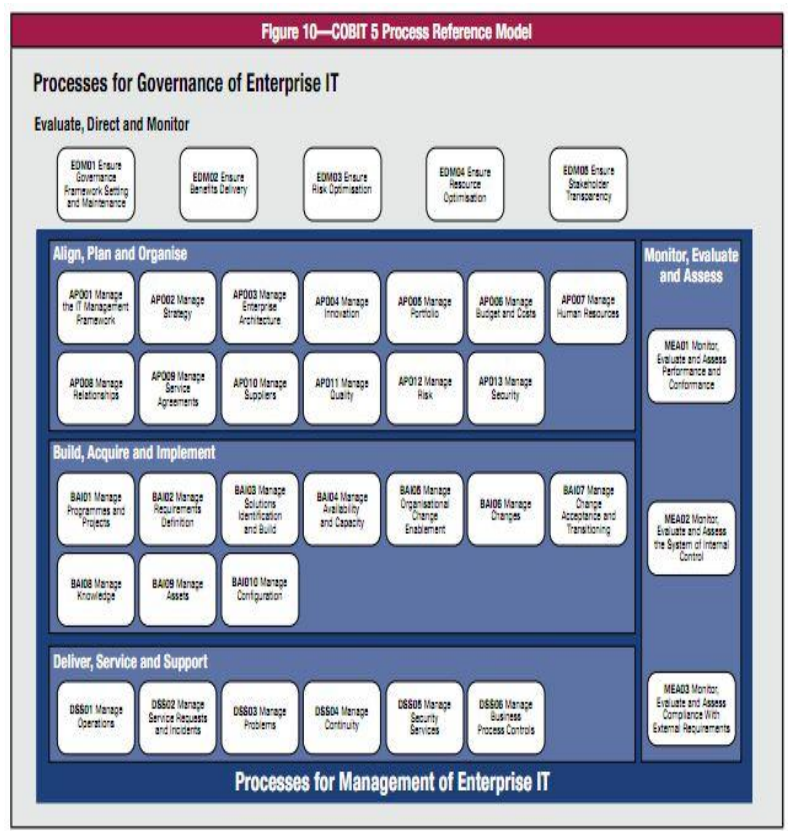

Gambar 4. Kerangka Kerja COBIT 5

Berdasarkan gambar 4 dapat dilihat bahwa fokus proses COBIT 5 digambarkan oleh model proses yang membagi TI menjadi 5 bagian dan 37 governance dan management processes.

\section{B. Pengumpulan Data}

Dalam penelitian ini data yang dikumpulkan adalah data primer dan data sekunder

1. Data primer adalah data yang diperoleh dari sumbersumber asli. Sumber asli disini diartikan sebagai sumber pertama dari mana data tersebut diperoleh. Sumber data primer dalam kegiatan penelitian ini didapat dari hasil wawancara, wawancara dilakukan dengan tujuan untuk mengetahui proses dan tahapan yang dilakukan sekarang berhubungan dengan pengelolaan sumber daya TI, proses pengambilan keputusan, proses pengelolaan investasi TI dan juga harapan yang ideal berdasarkan pandangan mereka, sekaligus menentukan faktor-faktor apa saja yang harus diperhatikan pada saat investasi TI akan dilakukan

2. Data sekunder adalah data yang diperoleh atau dikumpulkan peneliti dari sumber yang telah ada (peneliti sebagai tangan kedua). Data sekunder dapat diperoleh dari beberapa laporan yang telah dipublikasikan oleh PLN KITSBS secara internal atau instansi tertentu dan dapat dijaga keabsahannya.

\section{Alur Pikir}

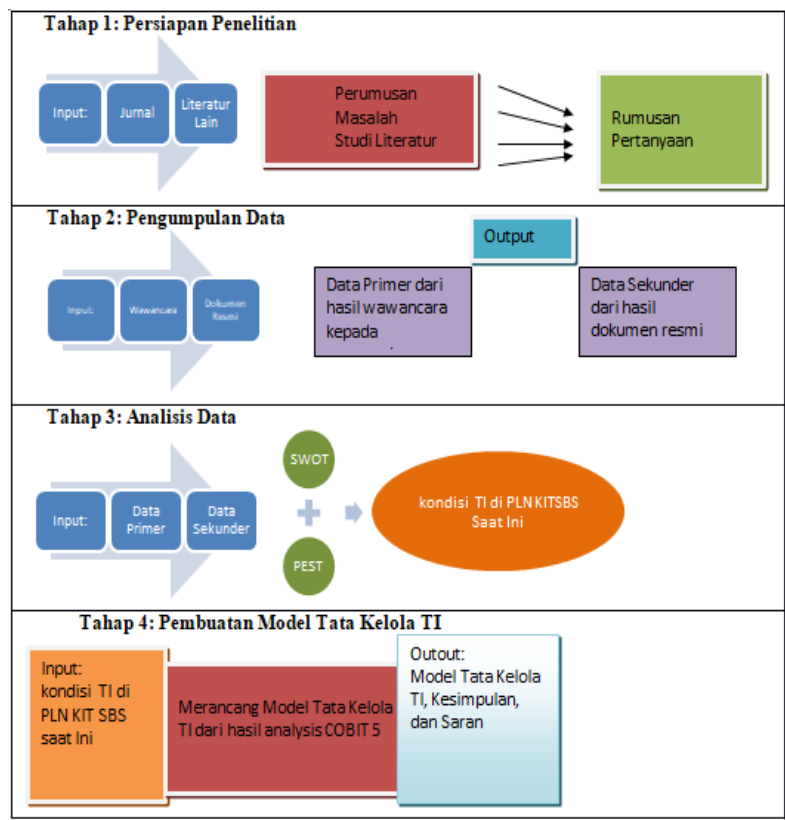

Gambar 5. Alur Pikir Pembuatan Model Tata Kelola TI di PLN KITSBS

Berdasarkan gambar 5 penelitian dimulai dengan pendefinisian masalah. Kemudian dilakukan reviewliteratur terkait dengan masalah yang diambil. Setelah itu dilakukan pengumpulan data, yang diperoleh melalui review dokumen, wawancara dengan narasumber dan observasi. Data yang diperoleh kemudian diolah dengan menggunakan COBIT 5, sehingga diperoleh strategi TI dan tujuan bisnis PLN KITSBS dan menganalisis tata kelola TI PLN KITSBS. Selanjutnya adalah merancang model tata kelola TI untuk PLN KITSBS. Tahapan terakhir adalah pembuatan kesimpulan dan saran dari penelitian.

\section{Pembahasan}

Model konseptual merupakan sebuah ilustrasi nyata dari logika yang digambarkan didalam beberapa konsep yank terhubung berdasarkan aspek teoritis dan hipotesis (Efendi, M 2012). Pada penelitian ini model konseptual dapat dilihat pada gambar 3.1. Model konseptual yang dihasilkan dari penelitian kali ini terdiri atas 3 blok, yaitu blok input, proses dan output. Ketiga blok tersebut 
dibuat berdasarkan tahapan yang terdapat pada COBIT 5 implementation.

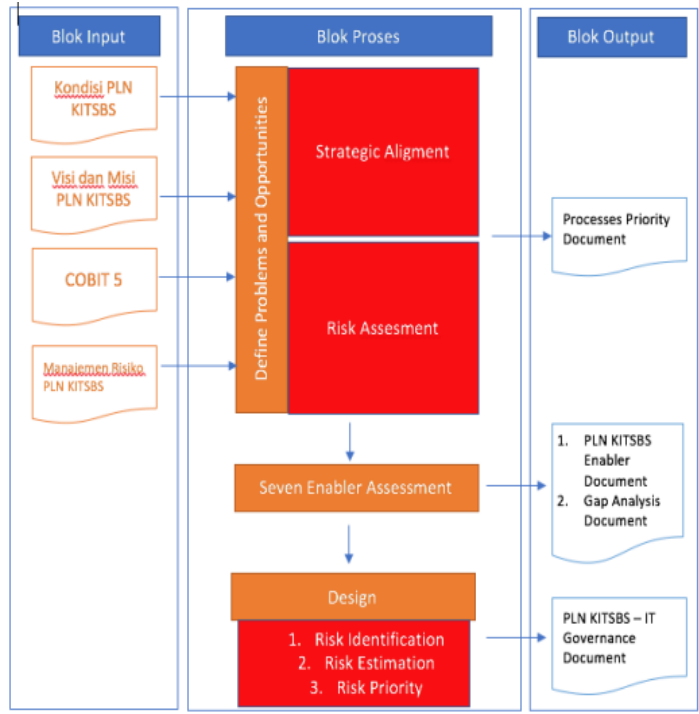

Gambar 6. Model Konseptual Tata Kelola TI PLN KITSBS

Blok Input terdiri dari keselarasan dari Visi dan Misi dengan TIK serta Manajemen Risiko. Keselarasan dari visi dan misi terhadap TIK dilakukan dengan mekanisme sebagai berikut:

a. Tujuan TIK yang dibuat harus sesuai dengan tujuan organisasi, sehingga tujuan TIK dan tujuan organisasi dapat selaras.

b. Pembuatan inisiatif TIK dengan rencana strategis organisasi harus selaras.

Kemudian bagian lainnya dari Business Input adalah Manajemen Risiko, manajemen risiko dalam model ini mencakup penentuan prioritas risiko dalam pengelolaan TIK oleh PLN KITSBS yang mencakup atas risiko proyek, risiko atas informasi, dan risiko atas keberlangsungan layanan.

1. Risiko atas proyek dibuat untuk menghindari kemungkinan terjadinya proyek TIK yang tertunda penyelesaiannya, biaya pengerjaan TIK yang melebihi perkiraan serta hasil akhir dari proyek yang tidak sesuai dengan spesifikasi yang telah ditentukan di awal.

2. Risiko atas informasi dibuat untuk menghindari sebuah tindakan akses ilegal terhadap aset informasi, tindakan ilegal yang dilakukan dapat berupa penggunaan informasi bahkan pengubahan informasi untuk keperluan yang tidak sebagaimana mestinya.

3. Risiko atas keberlangsungan layanan adalah untuk menjamin layanan TIK selalu tersedia sehingga hal seperti layanan TIK yang sama sekali tidak dapat berjalan tidak akan terjadi lagi.

Pada blok proses dilanjutkan dengan kegiatan assessment yang dilakukan dengan membuat instrumentkuisionerexisting penerapan TIK di PLN KITSBS untuk selanjutnya dianalisa, sehingga akan diketahui kondisi Tata Kelola TI di PLN KITSBS baik dari kondisi strategicalignment dan kondisi manajemen risiko yang ada di PLN KITSBS. Hasil assessment dari masing-masing proses tersebut adalah hasil analisa mengenai proses prioritas COBIT 5 yang akan menjadi lingkup penelitian di PLN KITSBS. Proses berikutnya melibatkan hasil assessment tersebut yang akan dianalisa dengan melakukan assessment Seven enabler COBIT 5, sehingga menghasilkan kondisi seven enable rexisting dan gap analisis mengenai kondisi existing dengan kondisi ideal pada COBIT 5 yang akhirnya dilanjutkan kepada proses perancangan tata kelola TI PLN KITSBS pada domain COBIT 5 berbentuk usulan people, process dan technology yang merajuk kepada sevenenabler ideal dari COBIT 5.

Sementara itu pada blok output dari model konseptual Tata Kelola TI ini menjelaskan apa saja artefak-artefak yang akan dihasilkan dalam bentuk dokumen-dokumen Tata Kelola TI yang sesuai dengan prinsip dan tujuan dari PLN KITSBS.

\section{Kesimpulan}

Berdasarkan hasil pembahasan di atas maka dapat ditarik beberapa kesimpulan, yaituModel konseptualtata kelola TI yang didasar ataskerangka kerja COBIT 5 dan hasil analisis penerapan tata kelola TI di PLN KITSBS, dapat menjadi acuan sebagai solusi pembuatan tata kelola TI di PLN KITSBS, sehingga model konseptual ini dapat menjadi pemahaman awal dalam pengembangan tata kelola TI bagi PLN KITSBS.

Saran pengembangan model konseptual ini adalah diperlukan penelitian yang lebih lanjut untuk menerapkan model yang telah dibuat kepada PLN Pembangkitan Sumatera Bagian Selatan. Dengan diterapkannya model konseptual yang telah dibuat, maka akan tahu tingkat keberhasilan dari model yang telah dibuat.

\section{Daftar Pustaka}

Board Broefing IT Governance $2^{\text {nd }}$ edition. 2003. IT GI. Effendi, M. 2012. Teori dan Pemodelan Sistem: Pengembangan Model, Retrieved from http://masud.lecture.ub.ac.id/files/2012/12/TPS-13PENGEMBANGAN-MODEL.pdf.

Grembergen, Wim Van. 2004. Strategien For Information Technology Governance, Idea Group Publishing.

Hojaji, F., \& Shirazi, M. 2012. A Design To Develop A New Comprehensive SOA Governance Framework, IJMIT.

Information System Audit and Control Association (ISACA). 2012.

"COBIT 5": A Business Framework for The Governance and Management of Enterprise IT", ISACA

Information System Audit and Control Association (ISACA). 2011. "COBIT 5": Enabling Processes", ISACA. 
Information System Audit and Control Association (ISACA). 2011. "COBIT 5": Process Reference Guide”, ISACA.

Moloeng, lexy J. 2004. Metode Penelitian Kualitatif. Rosda. Bandung.

Weill, Peter, \& Jeanne W. Ross. 2004. IT Governance: How Top Performance Manage TI Decision Rights For Superior Result. Harvard School Press. 